\title{
Pre-service Educational Assistants' Attitudes Toward Inclusion
}

\author{
John R. R. Freer \\ University of Windsor \& St. Clair College
}

\begin{abstract}
In recent years, educational assistants (EAs) have taken on an integral role in special education. They often work with the most challenging and vulnerable student population (i.e., students with exceptionalities). To prepare EAs, some of Ontario's publicly funded colleges have developed pre-service training programs. In Ontario, the number of students receiving special education services from kindergarten to Grade 12 is increasing, and policy trends are advocating for inclusion. Literature has suggested that educators' attitudes toward educational inclusion may impact the extent to which inclusive strategies are implemented. Despite the importance that EAs bring to the special education team, very few studies have investigated their attitudes toward inclusion. This qualitative study investigated four pre-service EAs' attitudes toward educational inclusion through the use of semi-structured interviews. Participants held mostly positive attitudes toward inclusion, but expressed concerns about implementation. Recommendations are made for policy, practice, and research based on three themes that emerged from the data.
\end{abstract}

Inclusionary approaches to special education have become the norm in many countries (Hamaidi, Homidi, \& Reyes, 2012; UNESCO, 1994). In fact, the Ontario Ministry of Education (OME) introduced the Ontario Equity and Inclusive Education Strategy in 2009. This initiative recognizes that inclusive education is "education that is based on the principles of acceptance and inclusion of all students, [wherein] students see themselves reflected in their curriculum, their physical surroundings and the broader environment, in which diversity is honoured and all individuals are respected" (OME, 2009, p. 2). Despite a general push for inclusive policies and practices such as this, understanding and implementation of the concept vary. Avramidis, Bayliss, and Burden (2002) suggested 
that inclusion is "a bewildering concept which can have a variety of interpretations and applications" (p. 158). At the most basic level, inclusion involves educating students with exceptionalities alongside their peers in general education classes (GECs). There is a debate in the literature among those who believe all students with exceptionalities should be in GECs (e.g., see Bennett, 2009) and those who believe specialized or segregated classes offer much-needed individualized attention for students with exceptionalities (e.g., see Kauffman, Bantz, \& McCullough, 2002). The debate over service delivery, however, is only one aspect of inclusion. It has been suggested that successful inclusion requires students with exceptionalities to have feelings of belongingness in their classes and schools (Specht \& Bennett, 2013). Furthermore, the Canadian Research Centre on Inclusive Education (2017) has pointed out that successful inclusion is made up of (a) supportive environments, (b) positive relationships, (c) feelings of competence, and (d) opportunities to participate. Achieving this level of inclusion requires a team approach. An effective special education team includes several highly specialized professionals working in concert (e.g., parents, teachers, educational assistants, principals, speechlanguage pathologists).

The special education system in Ontario, Canada, has evolved from a system of categorization and exclusion to one that promotes inclusive ideals. In fact, the Ontario Ministry of Education (OME) requires placement in a GEC to be considered before less inclusive alternatives (OME, 2007a). This mandate reinforces a least restrictive environment approach to service delivery. A least restrictive environment approach acknowledges a range of options outside of the GEC when making decisions about the placement of students with exceptionalities (e.g., a fully separate classroom or the GEC with withdraw support; Rozalski, Stewart, \& Miller, 2010). Nevertheless, the vast majority of students with special education needs are being educated alongside their peers in GECs. In fact, the OME (2014, slide 2) reported "approximately $83 \%$ of all students ( $86 \%$ secondary) receiving special education programs and/or services are placed in regular classrooms for more than half of the instructional day." In order to promote student success and meet the growing needs of Ontario's inclusive milieu in special education, educational assistants (EAs) are employed to support students with special education needs. In the literature, EAs are also referred to as educational support staff, educational aides, teacher's assistants, learning support assistants, paraeducators, etc., depending on the geographical context. In Ontario, these professionals are commonly referred to as EAs. For the purpose of this paper, the term EA will be used in place of these and other professional titles. Many EAs receive little or no preparation for their position on the special education team (Wall, Davis, Winkler-Crowley, \& White, 2005). There continues to be a general call for better in-service and pre-service training for EAs in the literature, and many EAs have indicated their desire for further education in their field (Abbott, McConkey, \& Dobbins, 2011; Giangreco, Doyle, Suter, 2012; Glazzard, 2011; Moran \& Abbott, 2002). Research has shown that training EAs has led to improvements in self-esteem and an increase in EAs' confidence for their role in special education (Rose \& Forlin 2010).

Giangreco, Suter, and Doyle (2010) pointed out that "we continue to assign the least qualified personnel to students who present the most challenging learning and behavioral characteristics" (p. 51). In Ontario, however, relatively new post-secondary programs are 
addressing this social justice issue with specialized training for EAs. In recent years, Educational Support (ES) programs (previously referred to as EA programs) have been developed and are now offered at some publicly funded colleges in Ontario (referred to as Colleges of Applied Arts and Technologies-CAATs). These programs help to prepare prospective EAs for their future role on the special education team.

\section{EA Role Transformation}

In the past, the role of an EA was to carry out mundane clerical tasks (e.g., photocopying, organizing) in order to help the classroom teacher optimize his/her efficiency (Groom, 2006). Today, EAs play a central role in the implementation of special education services under the direction of the classroom teacher. EAs support students with exceptionalities in school to help ensure that these students are working toward achieving the goals set out in their individual education plan. In many cases, EAs are in contact with students who have exceptionalities more than are any other educational staff member in the school. As a result, EAs can have a tremendous impact on these students' academic and social experiences. In fact, researchers have recognized that EAs play a central role in the success of inclusive education (Groom \& Rose, 2005; Hemmings \& Woodcock, 2011).

As the EA profession has gone through this dramatic role transformation, growing pains have accompanied these developments. Challenges the EA profession continues to face include, but are not limited to: role confusion between teachers and EAs (Angelides, Constantinou, \& Leigh, 2009), student overreliance (Giangreco, Broer, \& Suter, 2011), lack of appreciation for EAs (Abbott et al., 2011), lack of preparation or training in special education (Breton, 2010; Fisher \& Pleasants, 2012), and difficulty establishing a professional identity (Trent, 2014). While it has been reported that EAs are most effective when structure and guidance are provided (Giangreco et al., 2011), more research needs to be conducted on the effectiveness of EAs in special education (Saddler, 2014). In particular, more research is needed that measures EAs' effectiveness with students who have special education needs in inclusive settings (Giangreco, 2010). Now that EAs play such an important role on the special education team, their attitudes toward inclusive education may also impact the implementation of inclusion, and therefore this study warrants attention.

\section{EAs' Attitudes Toward Inclusion}

There is an overall paucity of research examining EAs' attitudes toward inclusion. The limited literature on this topic suggests that in-service EAs believe their attitudes toward inclusion impact inclusive practices (Mackenzie, 2011; Symes \& Humphrey, 2011). Among the studies found in the literature examining EAs' attitudes toward inclusion, qualitative designs were mostly utilized (e.g., see Glazzard, 2011; Lawson, Parker, \& Sikes, 2006; Symes \& Humphrey, 2011). This is unusual in the larger context of attitudinal research on educational inclusion because "the dominant research tool in these [attitudinal] studies ... continues to be Likert-type scales and inventories offering pre-defined categories or statements, with respondents frequently being forced to make bi-polar choices" (Lawson et al., 2006, p. 57). One of the benefits of the qualitative 
designs (e.g., autobiographical, narrative, life history, phenomenology) is that these studies allowed the participants to provide depth in their responses that may not have been captured with an attitude metric alone.

One of the major findings from the literature has been that EAs' attitudes tended to be inconsistent. The literature suggests that EAs generally supported the idea of inclusion, but often had concerns when considering the implementation of this concept (Mackenzie, 2011; Sikes, Lawson, \& Parker, 2007). Sikes et al. (2007) called this "the 'Yes, buts' of inclusion" (p. 360). For example, "yes, inclusion is the ideal, but sometimes it is not a practical option." These were not the only inconsistencies among EAs' attitudes toward inclusion. Glazzard (2011) found EAs' attitudes toward inclusion were mixed (i.e., positive, negative, and ambivalent). Bennett and Gallagher (2013) found that EAs held positive attitudes toward educational inclusion, but not toward community inclusion. Overall inconsistencies observed in the literature may be a result of participants' understanding of the term inclusion. Lawson et al. (2006) found that EAs had difficulty defining inclusion, which is not surprising given that the term inclusion can be polysemous. For this reason, participants in the current study were first asked to share their definition of inclusion before sharing their attitudes toward inclusion.

It is evident from the literature that EAs' experiences had a large impact on their attitudes toward inclusion. Symes and Humphrey (2011) found that EAs who were working in inclusive settings generally held more positive attitudes toward inclusion. This finding is in line with mere exposure theory (Zajonc, 2001), which suggests that simply being exposed to an attitude object (i.e., inclusion) can enhance attitudes. It seems, however, that all types of experiences can impact EAs' attitudes toward inclusion. For example, Lawson et al. (2006) had participants discuss their experiences with disability inside and outside of their school and found that the EAs' experiences had a strong and positive influence on their attitudes toward educational inclusion. It stands to reason that experiences prior to working as an EA may also influence EAs' attitudes toward inclusion. For this reason, Mackenzie (2011) collected data on participants' life histories and discovered that early experiences had an impact on the EAs' attitudes toward inclusion. In fact, all 13 of the EAs in her study had experiences with disability (e.g., a family member) and many acknowledged this as a reason why they were interested in the field of special education in the first place.

In their review of the literature, Giangreco et al. (2010) pointed out that the $21 \mathrm{st}$ century has brought an increase in publications addressing issues related to the work of EAs. This increased interest among scholars seems promising and may reflect the growing importance of EAs in special education. Existing literature has suggested that educators' attitudes toward inclusion can greatly impact the extent to which inclusionary practices are applied (Avramidis, Bayliss, \& Burden, 2000; Avramidis \& Norwich, 2002; Lawson et al., 2006). Existing research further suggests that inclusive practices are impacted by educators' attitudes during pre-service training. For instance, Costello and Boyle (2013) pointed out that "the attitudes held by pre-service teachers have been shown to affect their willingness and ability to implement an inclusive approach to education." (p. 129). Since EAs work directly with students who have exceptionalities, their attitudes have the potential to greatly impact these students' experiences of inclusion. Examining the attitudes of pre-service EAs is particularly important because "pre-service training may be 
the optimum time to address educators' concerns and change any negative attitudes about inclusive education" (Ajuwon et al., 2012, p. 101). Previous studies investigating EAs' pre-service training have largely done so by asking participants to reflect on their preservice experiences retrospectively (e.g., see Breton, 2010; Burgess \& Mayes, 2009). The current study differs insofar as the participants were pre-service EAs at the time of data collection. It seems reasonable that ES students' pre-service experiences may have an impact on their understandings of, and attitudes toward inclusion. After an extensive review, I have not found any research on ES programs offered at CAATs across the province of Ontario. It is imperative, however, that this gap in the literature be addressed and pre-service EAs' perspectives be represented in the literature.

\section{Method}

To investigate ES students' attitudes toward inclusion, I conducted a generic qualitative study (Kahlke, 2014). Percy, Kostere, and Kostere (2015) have pointed out that this research design is appropriate for attitudinal research and that this design often employs common methods (e.g., semi-structured interviews, thematic analysis). Guided by a social constructivist epistemology, I first sought to discover participants' understandings of educational inclusion. Once this was established, participants were asked about their attitudes toward the concept. Finally, participants were asked what they believed were facilitating factors and barriers to educational inclusion.

\section{Procedure}

Students attending one of two ES programs at the same CAAT in Ontario, Canada, were invited for an interview via their online learning management system. These two programs included a two-year program and a one-year intensive program for those with advanced experience or education. In order to protect the participants' identities, the CAAT will be referred to as Moxie College throughout this article. Data was gathered from participants using a demographic questionnaire and semi-structured interviews, which took approximately an hour to administer. A review process ensured that ethical guidelines were followed throughout the research process. Demographic information helped to contextualize participants' responses, which can be an important part of understanding others' lived experiences (McCormack, 2004). Due to the semi-structured nature of these interviews, prompts were used to elicit responses from participants. Seven semi-structured interview questions (see Appendix) were developed with some guidance from studies that involved similar research inquires (Glazzard 2011; Hemmings \& Woodcock, 2011; McCray \& McHatton, 2011).

Interviews were conducted face to face (in person or online), were audio recorded, and transcribed verbatim. In addition, anecdotal notes on non-verbal cues were recorded in order to better understand the participants' responses. Participants had the opportunity to read over the interview transcripts to ensure their accuracy. This member-checking process helped to ensure that I did not misrepresent the views of the participants. All four participants agreed that the transcripts were complete, accurate, and reflected their true attitudes toward educational inclusion. After member checking, the participants gave me their consent to continue with the analysis of the data. Thematic analysis was employed, 
specifically the use of inductive analysis - a technique for coding data without predetermined categories (Braun \& Clarke, 2006; Percy et al., 2015). Transcribed interviews were read over several times in order to locate themes from the data (McCormack, 2000). These themes are presented in the Discussion section.

\section{Participants}

Students in their final semester of an ES program were asked to participate. The students who received the recruitment information had completed the majority of their program, which included specialized coursework and field placement experiences. In total, I recruited four participants from a group of 65 full-time students. The four participants were all female with an average age of 43.75 (ages ranged from 34 to 49). Therefore, all the participants were mature students who had some very rich life experiences from which to draw. This presents a limitation of this research study, that is, the four participants by no means represent the attitudes of the population of interest (i.e., final year ES students across Ontario). In fact, the participants were not representative of the majority of those in the ES programs at Moxie College, which consisted of mostly females between the ages of 21 and 25 years of age. The findings from this study cannot be generalized, but instead provide a starting point by giving ES students in Ontario a voice in the literature. Research with more representative samples would help to further address this gap. In order to protect the participants' identities, all of them have been assigned pseudonyms. See Table 1 for a summary of the participants' background.

Table 1.

Study Participants

\begin{tabular}{|c|c|c|c|c|c|}
\hline Name & Age & Program & $\begin{array}{l}\text { Background and } \\
\text { Qualifications }\end{array}$ & ES Field Placement & $\begin{array}{l}\text { Prior Experience } \\
\text { with Disability }\end{array}$ \\
\hline Anne & 49 & 2-year & $\begin{array}{l}\text { Bus driver for students with } \\
\text { exceptionalities }\end{array}$ & $\begin{array}{l}\text { Various special needs; } \\
\text { GEC; }\end{array}$ & $\begin{array}{l}\text { Father, daughter, } \\
\text { and friend's child }\end{array}$ \\
\hline April & 43 & 1-year & $\begin{array}{l}\text { Private school teacher; } \\
\text { History degree }\end{array}$ & Autism; GEC & $\begin{array}{l}\text { Former students in } \\
\text { private school }\end{array}$ \\
\hline Kelly & 49 & 1-year & $\begin{array}{l}\text { Classroom volunteer; } \\
\text { English degree }\end{array}$ & $\begin{array}{l}\text { Various special needs; } \\
\text { self-contained and } \\
\text { GEC }\end{array}$ & $\begin{array}{l}\text { Son and two } \\
\text { brothers }\end{array}$ \\
\hline Grace & 34 & 1-year & $\begin{array}{l}\text { Support worker for disability } \\
\text { service organization; } \\
\text { Psychology degree; Human } \\
\text { Behaviour certificate; } \\
\text { General Arts and Science } \\
\text { diploma }\end{array}$ & $\begin{array}{l}\text { Non-verbal DD and } \\
\text { cerebral palsy; GEC }\end{array}$ & $\begin{array}{l}\text { Clients at disability } \\
\text { service organization }\end{array}$ \\
\hline
\end{tabular}

Note: All participants were females in the final semester of their program. DD= developmentally delayed.

Anne. Anne was a 49-year-old woman and was in the second year of Moxie College's two-year ES program. Anne's father had a physical disability and her daughter had been identified as gifted. Anne also had a good friend who had a child with a disability. Her field placements in the ES program had all been in GECs supporting students with special education needs. These experiences ranged from junior kindergarten to high school, which 
in Ontario typically ranges from ages 4 to 18 . Throughout her three field placement experiences, she worked closely with students who had developmental, physical, behavioural, and learning disabilities. Prior to her experiences in the ES program, Anne worked for more than 25 years as a bus driver for students with exceptionalities.

April. April was a 43-year-old woman and was enrolled in Moxie College's oneyear intensive ES program. Prior to enrolling in the ES program she completed a degree in History. Her field placement in the ES program was in a GEC, supporting two boys with autism spectrum disorder. Prior to her experiences in the ES program, April worked as a teacher. She taught students with and without exceptionalities in a small class at a private school.

Kelly. Kelly was a 49-year-old woman and was enrolled in Moxie College's oneyear intensive ES program. Prior to enrolling in the ES program she completed a degree in English. At the time of data collection she was also taking online courses about inclusion, which was above and beyond her ES coursework at Moxie College. Her son and two brothers had all been diagnosed with learning disabilities. Through her field placement experiences, Kelly worked in both self-contained classes and GECs. In the GEC, she worked in an elementary school with children who had learning disabilities, autism, and behavioural disorders. In the self-contained class, she worked in a high school with youth who were medically fragile, developmentally delayed, and had high needs. Outside of the ES program, Kelly volunteered in an elementary school for approximately six years.

Grace. Grace was a 34-year-old woman and was enrolled in Moxie College's one-year intensive ES program. Prior to enrolling in the ES program she completed: a degree in Psychology, a Human Behaviour Certificate, and a General Arts and Science Diploma. Grace's field placement experiences in the ES program had all been in GECs. Her first placement was in junior kindergarten with a student who was non-verbal and diagnosed with a developmental disability. Her second placement was in Grades 3 and 6 working with students who were diagnosed with cerebral palsy. Prior to her experiences in the ES program, Grace worked as a support worker for a disability service organization for 16 years.

\section{Findings}

The responses shared by these four participants delved deeply into their personal lived experiences. This section presents participants' understandings of educational inclusion, their expressed attitudes toward including students with exceptionalities in GECs, and the facilitating factors and barriers that participants identified in relation to inclusive education.

\section{Understandings of Inclusion}

Glazzard (2011) pointed out, "There is a lack of shared understanding of what constitutes inclusion" (p. 57). Therefore, it is not surprising that all four participants had slightly different understandings of educational inclusion, despite their shared educational experience as final semester ES students. Nevertheless, some participants acknowledged that the ES program helped to shape their understanding of the concept. For example, 
despite her previous experience as a teacher in a private school setting, April credited the ES program at Moxie College for her current understanding of educational inclusion. She admitted, "To be honest, before this program I did not know much about it [educational inclusion]." An acknowledgment such as this helps to point out the importance of ES programs in preparing prospective EAs to work on the special education team.

All of the participants emphasized service delivery in one way or another. April emphasized the importance of including all students in the GEC when she stated, "Educational inclusion, to me, means that all students are in one classroom together, regardless of any disparities in their disability [sic]." As the conversation developed, April clarified that inclusion is not just about students with exceptionalities. She explained, "[Educational inclusion], from what I understood, is setting [the classroom] up so that every student has the opportunity to succeed in learning." Kelly, on the other hand, viewed the least restrictive environment as inclusive. She asserted that inclusion was a malleable term that could mean different things for different students, when she concisely stated, "Inclusion to me ... is involving the student [with an exceptionality] in the setting that's best for their success."

Anne saw educational inclusion as more of a philosophy and not necessarily about the placement of students with exceptionalities. For Anne, this conclusion came from observing exclusion, in a so-called inclusive classroom (i.e., a GEC). She recalled an experience from her field placement:

I noticed that the student [with an exceptionality] was turned to face the EA and the EA was very much working one on one with the student [at the back of the class]. It was very difficult because I was thinking, "Wouldn't it be better to place the wheelchair in a different position or differently so she was actually more a part of the actual class?"

From her field placement experiences, Anne concluded that inclusion was more of a guiding philosophy than a location. She explained, "I think we can still achieve inclusion even if students go to a self-contained class because ... you can still include a selfcontained class in the spirit of the entire school." She summed up her definition of inclusion by stating, "Inclusion means that you treat everyone with respect and kindness." Grace also believed inclusion was more of an overarching philosophy than a location. She echoed the sentiments of Anne's experience by pointing out that it is not enough for students with exceptionalities to be included in the GEC, if they are excluded elsewhere. She said, "It [inclusion] is outside at recess time, in activities, and games in gym class. Inclusion should be everywhere really. It should be outside in the real world [too]."

\section{Attitudes Toward Inclusion}

Despite the various understandings of inclusion expressed by the participants, when asked about their attitudes toward educational inclusion, all of the participants spoke about their attitudes toward students being placed within the GEC. Overall, participants' attitudes toward inclusion were contingent on the severity of students' exceptionalities, and their lived experiences played an important role in attitude development. 
Contingent attitudes. In their responses, Anne, April, and Grace all acknowledged educational inclusion as a theoretical ideal. For example, April stated, "I think fundamentally my opinion is that we should always try to have them [students with exceptionalities] in an inclusive classroom first." On the other hand, Kelly was more skeptical of including students with exceptionalities in the GEC. Kelly said,

I struggle with it [inclusion] because sometimes ... I wonder if it is the best thing for the student [with an exceptionality]. I think that these kids are overwhelmed in [general] classrooms. I mean we are setting them up to fail.

As the discussions developed, however, it became clearer that all the participants had concerns about applying the theoretical concept of inclusion in practice. In particular, the participants had apprehensions about including students with complex needs. For example, Grace said,

I agree with inclusion to a point. High functioning [students] should be in the mainstream regular class ... and I think the severe students should be in a separate ... [learning environment] ... where they can benefit from the life skills program.

From her experiences, Grace believed that students with severe needs might not benefit the same way as others from being included in the GEC. She recalled a story from her first field placement experience that helped to shape her attitude toward educational inclusion:

There was this student [during field placement] who was non-verbal and who was developmentally delayed in all areas. For a student like that, I find it hard for them to be included in the classroom. I think they would benefit more in a contained classroom ... where they can get that one-on-one support and at their level as well.

Lived experiences. Consistent with previous studies examining in-service EAs' attitudes (e.g., see Mackenzie, 2011), past experiences had an influence on pre-service EAs' attitudes toward inclusion. April, Anne, and Kelly all shared how their early experiences helped to shape their attitudes toward inclusion.

April's experience teaching in a private school with small class sizes helped her to appreciate the importance of individualized support and differentiated instruction for students with diverse needs. She recalled:

I think definitely the initial experience I had in a classroom with some of the students that I taught certainly shaped how I felt about inclusion. In independent schools ... it is a very different scenario than school boards where there are twenty-five kids [in a class]. There were only eight kids in my class [at the private school, so] ... I had the time to be able to do one-on-one things with the students who were struggling or needing extra support.

Similarly, Anne's attitudes toward inclusion developed from her early experiences as a bus driver for students with exceptionalities. She recalled a pivotal experience she had with her son that helped to shape her attitude toward inclusion. She reminisced:

I started driving a school bus for special needs kids when I was 22 or 23 , so I was very young. I had a little baby and so this was just part of our daily life. We would go pick up these kids [students with exceptionalities] and bring them to school, no big deal. When my son started to go to kindergarten ... he was super excited. One day he 
came up to me and he asked, "When do I go pick up my wheelchair?" I looked at him and I said, "What do you mean? You don't need a wheelchair." He said, "All the kids who go to school have a wheelchair. When do I get my wheelchair?" My son saw the cool wheelchair; he never realized that Joey couldn't walk. What he saw was that Joey got to go around in a wheelchair and that was pretty cool. So that really made me realize that there was no difference between him and the kids [with exceptionalities].

Through their experiences, Anne and April developed positive attitudes toward inclusion, but Kelly had a very different experience with her son. She recalled her experiences with him through school:

With my son it kind of really defined it for me when he was [slight pause while pondering the correct age] ... 17. When he was little he hated being pulled out [of class] because then he felt different ... but in high school with the GLE [General Learning Environment] program [a self-contained class], where they pull out kids that have some kind of learning disability and provide more support. That classroom is his favourite classroom because there he feels normal.

In addition to outside experiences, the ES program also played a role in shaping participants' attitudes toward educational inclusion. In some cases, observing the challenges of inclusion on field placement lead to less optimistic attitudes toward including students with exceptionalities in a GEC. For example, Anne explained that her attitudes toward educational inclusion had changed as a result of the ES program. She shared:

I [now] recognize that there are some needs that are probably addressed better in a contained class, where I may not have felt that before being in a classroom. So I can see that there are benefits to contained classes now, but I still think that if inclusion is an option, it is probably the better option.

For others, the ES program helped to enhance attitudes toward inclusion. For example, Grace discussed how the ES program challenged her preconceived notions about inclusion. She said, "Before [I enrolled in the ES program] I honestly thought that ... even if [a student had] a slight disability they were [to be placed] in a different classroom."

\section{Facilitating Factors and Barriers to Inclusion}

In the interviews, participants identified facilitating factors and barriers to educational inclusion. Facilitating factors for inclusion identified by the participants included: (a) appropriate support for inclusion, (b) creating an inviting environment, and (c) student training regarding disability. The barriers for inclusion identified by the participants included: (a) poor attitudes toward disability, (b) power dynamic issues between teachers and EAs, and (c) lack of training in special education and evidencebased strategies. These findings can be compared with those of a similar study done with in-service EAs. Glazzard (2011) reported that EAs identified the importance of one-onone support and teamwork between teachers and EAs. On the other hand, participants suggested that compensatory special education policies, parental resistance, and lack of resources posed barriers to an inclusionary approach. 


\section{Discussion}

This study gives a voice to ES students in Ontario for the first time in the literature. All four women recognized that the ES program had an impact (to varying degrees) on their understanding of, and attitudes toward educational inclusion. Each of the participants expressed their own understanding of inclusive education, which supports previous findings that suggest this concept is not uniformly understood (Avramidis et al., 2002; Glazzard, 2011). The findings suggest that attitudes toward inclusion were initially developed from prior lived experiences, but that the pre-service program helped to shape participants' attitudes toward inclusion. Specifically, knowledge and practical experiences within the ES program had an influence on the participants' attitudes toward educational inclusion. In fact, all four of the participants' responses placed a heavy emphasis on the field placement component of the program. This is an exciting finding because it suggests that EAs' attitudes can change and that pre-service programs present an opportunity to address attitudes toward inclusion.

Three major themes emerged from the data: (a) the early development of "yes, but ..."; (b) EAs: ambassadors for inclusion; and (c) a prepared special education team. Next, these themes will be presented alongside recommendations for policy, practice, and research.

\section{The Early Development of "Yes, but ..."}

Overall, most of the interviewees supported the idea of educational inclusion, but reported concerns about implementing inclusive practices. This distinction between belief and behaviour led to "yes, but ..." statements about inclusion from the participants. For example, Kelly said regarding inclusion, "Yes, but sometimes I think it [inclusion] points out their disability more than it includes them." Like working EAs (Mackenzie, 2011; Sikes et al., 2007), the ES students in this study also struggled to reconcile the ideals of inclusion with the challenges they experienced in practice. These findings demonstrate that "the 'yes, buts' of inclusion" (Sikes et al., 2007, p. 360) are present at the pre-service level. It is recommended that future research examine special educators' applications of inclusion in order to identify and promote best practices. These studies need to be disseminated to teachers, EAs, and other special education team members in order to bridge the gaps between theory and practice.

The most prevalent practical concern identified by the participants was regarding the inclusion of students who have complex needs. These responses echo concerns about full inclusion presented by Kauffman et al. (2002): that is, a belief that some students with exceptionalities may not flourish in a GEC. One policy recommendation would be for the OME to develop documentation on the best practices for including students with high needs. If educators, such as the participants in this study, are uneasy about including students with complex needs, this may pose a barrier to equity and inclusion for these students. These concerns can also be addressed within pre-service programs (e.g., ES programs) by providing courses that offer practical strategies to enhance inclusive education for students of all ability levels. "Yes, but ..." statements serve to critically analyze the effectiveness of educational inclusion in practice, which if discussed during pre-service coursework, may better prepare special educators to work toward more inclusive ideals in the future. 


\section{EAs: Ambassadors for Inclusion}

Not surprisingly, the ES students interviewed placed a strong emphasis on the value of educational support, especially with regard to the role of the EA on the special education team. Much like in-service EAs (Mackenzie, 2011), the ES students viewed well trained EAs as essential to the successful implementation of inclusive education. For example, Grace argued that EAs are the foremost experts on their students because they work so closely with them. In addition, April proclaimed, "Having an EA in every classroom would be amazing." She further reflected on the idea that without the support of an EA, placement in the GEC would be impossible for some students. April said, "One of the students that I work with, for instance ... is considered low functioning [and] nonverbal. I cannot imagine him being in an inclusive environment without the support he is getting." The participants in this study saw the role of an EA as essential to including students with exceptionalities. This finding is in line with those of Groom and Rose (2005), who discovered that several key stakeholders in education identified EAs as central to the success of inclusive education.

Despite the belief that EAs play a central role on the special education team, all of the participants in this study felt that trained EAs were being underutilized. This finding was similar to that of Mackenzie (2011), who found EAs resented the fact that their work was considered by many in the school to be of lower status compared to the work of teachers. This has not been found in all studies. For example, Symes and Humphrey's (2011) found EAs felt respected by their colleagues. In order to be taken seriously as professionals, EAs need opportunities to make meaningful contributions, in which they can share their specialized knowledge and skills with the special education team. Since EAs are often responsible for supporting students with exceptionalities, they should be consulted more frequently. For example, EAs should be invited to all the meetings (e.g., identification, placement, and review committee meetings; transition meetings) and included in the development and revision process of individual education plans for the students to whom they are assigned. When EAs are not invited or called upon to contribute, it neglects front line input about students' needs. Part of this problem may stem from power dynamic and/or role confusion between teachers and EAs (Angelides et al., 2009).

In order to avoid role confusion, it is recommended that the OME clearly identify the roles and duties of an EA. This definition will have to build in flexibility, since EAs' responsibilities are often complex, diverse, and dependent on the student(s) to whom they are assigned. Current documents are outdated and make little reference to EAs, if any. In fact, in the Shared Solutions document (OME, 2007b), an appendix listing the roles and responsibilities of special education team members does not include EAs. Education for All (OME, 2013b) and the Individual Education Plan Resource Guide (OME, 2004) provide a brief overview of the EA role. Most recently, the Special Education in Ontario Policy and Resource Guide provides a bit more information on educational assistants (OME, 2017). These guidelines are helpful in asserting that EAs are members of the special education team, but it is recommended that further documentation be developed. Such documentation would need to expand upon the EA's role and provide clearer discussion of the teacher-EA working dynamic. This is especially important, as professional collaboration is now mandated under Policy Program Memorandum 159 (OME, 2016). In recent years, EAs 
have become further entrenched in special education and thus up-to-date documentation would be beneficial for all stakeholders in special education.

Establishing EAs as respected professionals is vital. Therefore, another recommendation would be to establish a professional association for EAs, similar to that of the Ontario College of Teachers or the College of Early Childhood Educators. The idea to establish a governing body for EAs was discussed briefly at the 2014 Ontario Council for Exceptional Children Annual Special Education Conference (Fitzgibbon, Hansen, Barlow, \& Newman, 2014). A provincial association for EAs could govern and regulate practices for the profession across the province.

Finally, future research in special education should include the voice of EAs more often. Giangreco et al. (2010) found that "the rate of research on [EAs] ... has more than doubled since the last review [2001]. This suggests that [EA] ... issues are a growing area of interest and importance in the field" (p. 44). Despite this recent increase, EAs' voices are still under-represented in the special education literature. Future studies should consider pre-service and in-service EAs' perspectives when investigating a wide variety of special education topics (e.g., inclusion, collaboration, training).

\section{A Prepared Special Education Team}

Researchers are continually refining the identification of best practices in special education. As might be expected, the participants in the current study emphasized the importance of all educators having up-to-date training in order to implement best practices with students who have exceptionalities. For example, Grace took notice of non-evidencebased practices being utilized. Participants indicated that EAs, teachers, and even principals in some cases did not seem to have adequate training in special education.

Standardized pre-service training for EAs is not mandated. Even in Ontario, where ES programs exist, EA hiring practices do not restrict school boards to hiring ES graduates exclusively. In fact, in some cases a high school diploma is all that is required. It is recommended that all school boards across the province develop a hiring policy that provides a preference to those who have graduated from an ES program. In addition, as EAs take on a more instructional role, greater in-service training opportunities are recommended. Several studies, including the current study, have indicated that EAs have a desire for more training (Abbott, et al., 2011; Glazzard, 2011). Once hired, teachers have far more opportunities for in-service training (e.g., additional qualification courses). In addition, EAs need to receive more support for their expanding role in special education. It is recommended that EA-specific additional qualification courses (e.g., autism specialist, behaviour specialist) be created in order to enhance the in-service training opportunities for EAs. In addition, some of these courses could offer interprofessional training for EAs and teachers in order to facilitate professional collaboration.

\section{Conclusion}

This study allowed participants the opportunity to reflect upon their lived experiences and consider their attitudes toward inclusive education. Further, it helped to point out the importance of EAs in special education and the relevance of ES programs in 
Ontario CAATs. Trends in provincial policies (e.g., Policy Program Memorandum 119) suggest that the province of Ontario will continue to promote inclusive education into the foreseeable future (OME, 2013a). The participants in the current study identified that there is still a great deal of room for improvement as we strive for more inclusive education in Ontario. Understanding pre-service and in-service EAs' attitudes toward inclusion can impact the extent to which these special educators implement inclusive ideals. Together with the special education team, ES graduates (as working EAs) will play an important role in the pursuit of truly inclusive education for all students.

\section{References}

Abbott, L., McConkey, R., \& Dobbins, M. (2011). Key players in inclusion: Are we meeting the professional needs of learning support assistants for pupils with complex needs? European Journal of Special Needs Education, 26, 215-231.

Ajuwon, P. M., Lechtenberger, D., Griffin-Shirley, N., Sokolosky, S., Zhou, L., \& Mullins, F. E. (2012). General education pre-service teachers' perceptions of including students with disabilities in their classrooms. International Journal of Special Education, 27(3), 100-107. Retrieved from http://www.internationaljournalofspecialeducation.com

Angelides, P., Constantinou, C., \& Leigh, J. (2009). The role of paraprofessionals in developing inclusive education in Cyprus. European Journal of Special Needs Education, 24, 75-89. doi:10.1080/08856250802596741

Avramidis, E., Bayliss, P., \& Burden, R. (2000). Student teachers' attitudes towards the inclusion of children with special educational needs in the ordinary school. Teaching and Teacher Education, 16, 277-293. doi:10.1016/S0742-051X(99)00062-1

Avramidis, E., Bayliss, P., \& Burden, R. (2002). Inclusion in action: An in-depth case study of an effective inclusive secondary school in the south-west of England. International Journal of Inclusive Education, 6(2), 143-163. doi:10.1080/13603110010017169

Avramidis, E., \& Norwich, B. (2002). Teachers' attitudes towards integration / inclusion: A review of the literature. European Journal of Special Needs Education, 17(2), 129-147. doi:10.1080/08856250210129056

Bennett, S. (2009). Including students with exceptionalities. What works? Research into practice (Literacy and Numeracy Secretariat Research Monograph \#16). Toronto, ON: Government of Ontario. Retrieved from the OME website, http://www.edu.gov.on.ca/eng/literacynumeracy /inspire/research/Bennett.pdf

Bennett, S. M., \& Gallagher, T. L. (2013). High school students with intellectual disabilities in the school and workplace: Multiple perspectives on inclusion. Canadian Journal of Education, 36(1), 96124. Retrieved from http://www.cje-rce.ca/index.php/cje-rce/article/view/1164/1463

Braun, V., \& Clarke, V. (2006). Using thematic analysis in psychology. Qualitative Research in Psychology, 3, 77-101. doi:10.1191/1478088706qp063oa

Breton, W. (2010). Special education paraprofessionals: Perceptions of preservice preparation, supervision, and ongoing developmental training. International Journal of Special Education, 25, 34-45. Retrieved from http://www.internationaljournalofspecialeducation.com

Burgess, H., \& Mayes, A. S. (2009). An exploration of higher level teaching assistants' perceptions of their training and development in the context of school workforce reform. Support for Learning, 24, 19-25. doi:10.1111/j.1467-9604.2009.01393.x 
Canadian Research Centre on Inclusive Education. (2017). Understanding inclusive education [Web page]. London, ON: Author. Retrieved from http://www.inclusiveeducationresearch.ca /about/inclusion.html\#top

Costello, S., \& Boyle, C. (2013). Pre-service secondary teachers' attitudes towards inclusive education. Australian Journal of Teacher Education, 38(4), 129-143. doi:10.14221/ajte.2013v38n4.8

Fisher, M., \& Pleasants, S. L. (2012). Roles, responsibilities, and concerns of paraeducators: Findings from a statewide survey. Remedial and Special Education, 33, 287-297. doi:10.1177/0741932510397762

Fitzgibbon, A., Hansen, K., Barlow, G., \& Newman, T. (November, 2014). Is it time for an educational assistant provincial association? Presented at the Ontario Council for Exceptional Children Conference.

Giangreco, M. F. (2010). Utilization of teacher assistants in inclusive schools: Is it the kind of help that helping is all about? European Journal of Special Needs Education, 25, 341- 345. doi: $10.1080 / 08856257.2010 .513537$

Giangreco, M. F., Broer, S. M., \& Suter, J. C. (2011). Guidelines for selecting alternatives to overreliance on paraprofessionals: Field-testing in inclusion-oriented schools. Remedial and Special Education, 32, 22-38. doi:10.1177/0741932509355951

Giangreco, M. F., Doyle, M. B., \& Suter, J. C. (2012). Constructively responding to requests for paraprofessionals: We keep asking the wrong questions. Remedial and Special Education, 33, 362-373. doi:10.1177/0741932511413472

Giangreco, M. F., Suter, J. C., \& Doyle, M. B. (2010). Paraprofessionals in inclusive schools: A review of recent research. Journal of Educational and Psychological Consultation, 20, 40-57. doi:10.1080/10474410903535356

Glazzard, J. (2011). Perceptions of the barriers to effective inclusion in one primary school: Voices of teachers and teaching assistants. Support for Learning, 26, 56-63. doi:10.1111/j.14679604.2011.01478.x

Groom, B. (2006). Building relationships for learning: The developing role of the teaching assistant. Support for Learning, 21, 199-203. doi:10.1111/j.1467-9604.2006.00432.x

Groom, B., \& Rose, R. (2005). Supporting the inclusion of pupils with social, emotional and behavioural difficulties in the primary school: The role of teaching assistants. Journal of Research in Special Educational Needs, 5, 20-30. doi:10.1111/j.1471-3802.2005.00035.x

Hamaidi, D., Homidi, M., \& Reyes, L. V. (2012). International views of inclusive education: A comparative study of early childhood educator's perceptions in Jordan, United Arab Emirates, and the United States of America. International Journal of Special Education, 27(2), 94-101. Retrieved from http://www.internationaljournalofspecialeducation.com

Hemmings, B., \& Woodcock, S. (2011). Preservice teachers' views of inclusive education: A content analysis. Australasian Journal of Special Education, 35, 103-116. doi:10.1375/ajse.35.2.103

Kahlke, R. (2014). Generic qualitative approaches: Pitfalls and benefits of methodological mixology. International Journal of Qualitative Methods, 13, 37-52.

Kauffman, J. M., Bantz, J., \& McCullough, J. (2002). Separate and better: A special public school class for students with emotional and behavioral disorders. Exceptionality, 10, 149-170. doi:10.1207/S15327035EX1003_1

Lawson, H., Parker, M., \& Sikes, P. (2006). Seeking stories: Reflections on a narrative approach to researching understandings of inclusion. European Journal of Special Needs Education, 21, 55-68. doi:10.1080/08856250500491823 
Freer

Mackenzie, S. (2011). "Yes, but ...": Rhetoric, reality and resistance in teaching assistants' experiences of inclusive education. Support for Learning, 26, 64-71. doi:10.1111/j.14679604.2011.01479.x

McCormack, C. (2000). From interview transcript to interpretive story: Part 1-Viewing the transcript through multiple lenses. Field Methods, 12, 282-297. doi:10.1177/1525822X0001200402

McCormack, C. (2004). Storying stories: A narrative approach to in-depth interview conversations. International Journal of Social Research Methodology, 7, 219-236. doi:10.1080 $/ 13645570210166382$

McCray, E. D., \& McHatton, P. A. (2011). "Less afraid to have 'them' in my classroom": Understanding pre-service general educators' perceptions about inclusion. Teacher Education Quarterly, 38(4), 135-155. Retrieved from http://www.jstor.org/stable/23479634

Moran, A., \& Abbott, L. (2002). Developing inclusive schools: The pivotal role of teaching assistants in promoting inclusion in special and mainstream schools in Northern Ireland. European Journal of Special Needs Education, 17, 161-173. doi:10.1080/08856250210129074

Ontario Ministry of Education (OME). (2004). The individual education plan (IEP): A resource guide. Toronto, ON: Government of Ontario. Retrieved from the OME website, http://www.edu.gov.on.ca/eng/general/elemsec/speced/guide/resource/iepresguid.pdf

Ontario Ministry of Education (OME). (2007a). Identification, placement, and review committee. Retrieved from the OME website, www.edu.gov.on.ca/eng/general/elemsec/speced /identifi.html

Ontario Ministry of Education (OME). (2007b). Shared solutions: A guide to preventing and resolving conflicts regarding programs and services for students with special education needs. Toronto, ON: Government of Ontario. Retrieved from the OME website, http://www.edu.gov.on.ca /eng/general/elemsec/speced/shared.pdf

Ontario Ministry of Education (OME). (2009). Quick facts: Ontario's equity and inclusive education strategy. Toronto, ON: Government of Ontario. Retrieved from the OME website, www.edu.gov.on.ca/eng/policyfunding/equityquickfacts.pdf

Ontario Ministry of Education (OME). (2013a). Developing and implementing equity and inclusive education policies in Ontario schools (Policy/Program Memorandum No.119). Retrieved from the OME website, http://www.edu.gov.on.ca/extra/eng/ppm/119.pdf

Ontario Ministry of Education (OME). (2013b). Education for all: The report of the expert panel on literacy and numeracy instruction for students with special education needs, kindergarten to Grade six. Retrieved from the OME website, http://www.edu.gov.on.ca/eng /general/elemsec/speced/LearningforAll2013.pdf

Ontario Ministry of Education (OME). (2014). Support every child, reach every student: An overview of special education [PowerPoint slides]. Retrieved from http://www.ldao.ca/wpcontent/uploads/Special-Education-Overview-Oct-2014.pdf

Ontario Ministry of Education (OME). (2016). Collaborative Professionalism. Retrieved from the OME website, http://www.edu.gov.on.ca/extra/eng/ppm/ppm159.pdf

Ontario Ministry of Education (OME). (2017). Special education in Ontario policy and resource guide. Retrieved from the OME website, http://edu.gov.on.ca/eng/document/policy/os /onschools_2017e.pdf

Percy, W. H., Kostere, K., \& Kostere, S. (2015). Generic qualitative research in psychology. The Qualitative Report, 20(2), 76-85. 
Rose, R., \& Forlin, C. (2010). Impact of training on change in practice for education assistants in a group of international private schools in Hong Kong. International Journal of Inclusive Education, 14, 309-323. doi:10.1080/13603110802504895

Rozalski, M., Stewart, A., \& Miller, J. (2010). How to determine the least restrictive environment for students with disabilities. Exceptionality, 18(3), 151-163. doi:10.1080/09362835.2010.491991

Saddler, H. (2014). Researching the influence of teaching assistants on the learning of pupils identified with special educational needs in mainstream primary schools: Exploring social inclusion. Journal of Research in Special Educational Needs, 14, 145-152. doi:10.1111/1471-3802.12019

Sikes, P., Lawson, H., \& Parker, M. (2007). Voices on: Teachers and teaching assistants talk about inclusion. International Journal of Inclusive Education, 11(3), 355-370. doi:10.1080/13603110701238819

Specht, J., \& Bennett S. (2013). Some thoughts on achieving inclusive schooling. Educational Watch: An Update on Inclusive Education, 4(3), 3-4. Retrieved from www.inclusiveeducationresearch.ca /docs/Education_Watch_Spring_2013.pdf

Symes, W., \& Humphrey, N. (2011). School factors that facilitate or hinder the ability of teaching assistants to effectively support pupils with autism spectrum disorders (ASDs) in mainstream secondary schools. Journal of Research in Special Educational Needs, 11, 153-161. doi:10.1111/j.1471-3802.2011.01196.x

Trent, J. (2014). 'I'm teaching, but I'm not really a teacher'. Teaching assistants and the construction of professional identities in Hong Kong schools. Educational Research, 56, 28-47. doi:10.1080/00131881.2013.874147

UNESCO. (1994). The Salamanca statement and framework for action on special needs education. Paris, France: Author. Retrieved from the UNESCO website, http://www.unesco.org/education /pdf/SALAMA_E.PDF

Wall, S., Davis, K. L., Winkler-Crowley, A. L., \& White, L. L. (2005). The urban paraeducator goes to college. Remedial and Special Education, 26(3), 183-190.

Zajonc, R. B. (2001). Mere exposure: A gateway to the subliminal. Current Directions in Psychological Science, 10, 224-228. doi:10.1111/1467-8721.00154

\section{Author's Note}

Correspondence concerning this article should be addressed to John R. R. Freer, University of Windsor, 401 Sunset Ave, Windsor, ON, N9B 3P4, Canada; or St. Clair College, 2000 Talbot Road West, Windsor, ON, N9A 6S4, Canada. Email: freerj@uwindsor.ca or jfreer@stclaircollege.ca 


\section{Appendix}

\section{Interview Questions}

1) How do you personally define educational inclusion?

2) Can you please tell me about your attitudes toward educational inclusion?

3) Who and what in your life do you think have influenced your attitudes toward inclusion?

4) What do you think is needed for inclusion to be successful?

5) What do you feel are some barriers to inclusion?

6) In an ideal world (without these barriers), what would inclusion look like?

7) Is there anything else you would like to share regarding your personal attitudes toward inclusive education? 